\title{
Behaviour of RC structures strengthened with prestressed CFRP laminates: a numerical study
}

\author{
José Sena-Cruz, Luis Correia
}

ISISE, University of Minho, Guimarães, Portugal

Paulo França

CEris, ICIST and FCEE, University of Madeira, Funchal, Portugal

Contacting author: jsena@civil.uminho.pt

\begin{abstract}
The externally bonded reinforcement (EBR) technique is one of the most widely used strategies for the flexural strengthening of reinforced concrete (RC) with fibre reinforced polymer (FRP) materials. The EBR technique offers several structural advantages when the FRP material is prestressed. The development of high shear stresses at the ends of the prestressed FRP material can cause premature FRP peeling-off failure. This premature failure can be delayed or even avoided with the use of special end-anchorage systems, like the mechanical anchorage (MA) system and the gradient anchorage (GA) system. This paper presents an experimental and a numerical study on RC slabs strengthened in flexure with prestressed carbon FRP (CFRP) laminate strips, namely: (i) one reference slab; (ii) one slab strengthened with nonprestressed externally bonded CFRP (EB-CFRP) laminate; (iii, iv) and two slabs strengthened with prestressed EB-CFRP laminates using the MA and GA systems. The performance of these simulations was compared with results of the slabs experimentally tested up to failure. Subsequently, these models were used on a parametric study that intended to investigate the influence of different parameters affecting the behaviour of the slabs strengthened with prestressed EB-CFRP laminates.
\end{abstract}

Keywords: CFRP; Prestress; Strengthening; RC structures; Numerical analysis; Parametric studies.

\section{Introduction}

Nowadays, Carbon Fibre Reinforced polymers (CFRP) composites are used for retrofitting reinforced concrete $(\mathrm{RC})$ structures due to its lightweight, high strength, high stiffness and durability. In general, CFRP composites are applied in the shape of laminate strips according to the externally bonded reinforcement (EBR) technique to increase the flexural capacity of RC elements. In some cases, it may be advantageous or even required to use the CFRP laminate strips with a prestressed state. Literature [1-3] reports several benefits when the combination of these two techniques (external prestress and EBR) are used, mainly, deflection and crack width reduction, more efficient use of concrete and FRP materials, delay in the onset of cracking and yielding initiation, reduction of premature debonding failure, and increase of the load carrying capacity (flexural and shear). In order to avoid a premature FRP peeling-off failure, special endanchorage systems are implemented at the ends of the prestressed FRP elements. Among all the commercially available anchorage systems, two are particularly relevant: (i) the mechanical anchorage (MA) system, which fixes the ends of the FRP reinforcement to the 
concrete substrate by means of metallic plates and bolts, and (ii) the gradient anchorage (GA) that uses the adhesive's ability to cure faster at high temperatures to create a non-mechanical anchorage.

The durability, short and long-term behaviour of RC slabs strengthened in flexure with prestressed CFRP laminate strips using the EBR technique was previously studied in the scope of the research project FRPreDur (FCOMP-01-0124-FEDER-028865). This paper presents the experimental and numerical studies on RC slabs strengthened in flexure with prestressed carbon FRP (CFRP) laminate strips, namely: (i) one reference slab; (ii) one slab strengthened with and non-prestressed externally bonded CFRP (EB-CFRP) laminate; (iii, iv) and two slabs strengthened with prestressed EB-CFRP laminates using the MA and GA systems. Numerical simulations were developed to better understand the obtained results with regard to the overall structural behaviour. Subsequently, a parametric study with the aim at investigating the influence of different parameters affecting the slab's behaviour, namely the prestress level and the CFRP geometry, is presented.

\section{Experimental programme}

The experimental program was composed of four RC slabs, as presented in Table 1: (i) one slab was used as reference specimen (TO_REF); (ii) one slab was strengthened with one laminate according to the EBR technique (TO_EBR); (iii, iv) and two slabs were strengthened with one EBR prestressed CFRP laminate strip, one using the mechanical anchorage system (TO_MA) and another one with the gradient anchorage system (TO_GA). The CFRP prestrain, $\varepsilon_{f, p}$, was measured with a strain gauge installed at its mid-span.

The geometry and test configuration adopted to assess the time-dependent (creep) behaviour and durability of the slabs are presented in Figure 1 . All slabs are $2600 \mathrm{~mm}$ long, $600 \mathrm{~mm}$ wide and $120 \mathrm{~mm}$ thick. Each slab was designed with five steel bars with a diameter of $8 \mathrm{~mm}(5 \phi 8)$ as bottom reinforcement and with

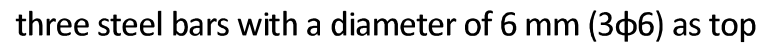
reinforcement. The concrete cover was $20 \mathrm{~mm}$. Stirrups of $\phi 6$ at $300 \mathrm{~mm}$ spacing were adopted as transverse reinforcement. Except for slab TO_REF, all slabs were strengthened with a $2200 \mathrm{~mm}$ long CFRP laminate strip, with a cross section of $50 \times 1.2[\mathrm{~mm}]$.

All the specimens were monotonically tested up to the failure using a four-point bending test configuration, under midspan displacement control at a rate of $1.2 \mathrm{~mm} / \mathrm{min}$. Instrumentation included (i) 5 linear variable differential transducers (LVDT1 to LVDT5, as shown in Figure 1 ); (ii) four TML BFLA-5-3 strain gauge sensors (SG1 to SG4) to record the CFRP strain; and (iii) a load cell to measure the applied load $F$.

Table 1. Experimental programme $\left(b_{f}=\right.$ strip width, $t_{f}=$ strip thickness, $\varepsilon_{f, p}=$ strip prestrain).

\begin{tabular}{cccc}
\hline Slab & $\begin{array}{c}\text { CFRP Strip } \\
{\left[\mathbf{b}_{\mathbf{f}} \times \mathrm{t}_{\mathbf{f}}\right]}\end{array}$ & Anchorage & $\begin{array}{c}\boldsymbol{\varepsilon}_{\mathrm{f}, \mathrm{p}} \\
{[\%]}\end{array}$ \\
\hline TO_REF & -- & -- & - \\
\hline T0_EBR & $50 \mathrm{~mm} \times 1.2 \mathrm{~mm}$ & -- & - \\
\hline TO_MA & $50 \mathrm{~mm} \times 1.2 \mathrm{~mm}$ & MA & 0.42 \\
\hline TO_GA & $50 \mathrm{~mm} \times 1.2 \mathrm{~mm}$ & GA & 0.40 \\
\hline
\end{tabular}

\subsection{Materials}

The material characterization included the evaluation of the mechanical properties of concrete, steel and CFRP laminate strips.

The compression tests used for the evaluation of the concrete were performed at the same age than the tests of the slabs. Four cylindrical concrete specimens with $150 \mathrm{~mm}$ of diameter and $300 \mathrm{~mm}$ of height were used to evaluate the modulus of elasticity and compressive strength through the LNEC E397-1993:1993 and NP EN 12390-3:2011 recommendations, respectively. An average modulus of elasticity of $30.0 \mathrm{GPa}(\mathrm{CoV}=2.9 \%)$ and an average compressive strength of about $42.2 \mathrm{MPa}(\mathrm{CoV}=0.7 \%)$ were obtained.

The tensile properties of the steel reinforcement were assessed throughout NPEN ISO 6892-1:2012 recommendations. Samples with $500 \mathrm{~mm}$ of length were used for each bar type ( $\phi 6$ and $\phi 8)$. An average modulus of elasticity $\left(E_{s}\right)$, yielding strength $\left(f_{s, y}\right)$, and ultimate tensile strength $\left(f_{s, u}\right)$ of $206.1 \mathrm{GPa}$ (CoV=0.4\%), 519.4 MPa (CoV=6.1\%) and $670.2 \mathrm{MPa}$ $(\mathrm{CoV}=5.1 \%)$, respectively, were obtained for the $\phi 6$ bar type. In the case of $\phi 8$ bar, $E_{S}=235.1 \mathrm{GPa}$ $(\mathrm{CoV}=4.6 \%), \quad f_{s, y}=595.9 \mathrm{MPa} \quad(\mathrm{CoV}=4.1 \%), \quad$ and $f_{s, u}=699.0 \mathrm{MPa}(\mathrm{CoV}=2.1 \%)$. 
The tensile properties of the CFRP laminate strip were evaluated using the standard ISO 527 5:1997. Six samples with $150 \mathrm{~mm}$ of length were used and, from the tensile tests, an average modulus of elasticity and ultimate tensile strength of $164.0 \mathrm{GPa}(\mathrm{CoV}=3.1 \%)$ and $2375.9 \mathrm{MPa}(\mathrm{CoV}=2.5 \%)$, respectively, were obtained.
The mechanical properties of the two-component epoxy adhesive (S\&P resin 220) used to bond the CFRP laminate strips to the concrete surface was not characterized. However, a previous experimental programme reported a modulus of elasticity of $7.2 \mathrm{GPa}$ (CoV=3.7\%) and a tensile strength of $22.0 \mathrm{MPa}$ (CoV=4.5\%), after 7 days of curing at $22^{\circ} \mathrm{C}[4]$.

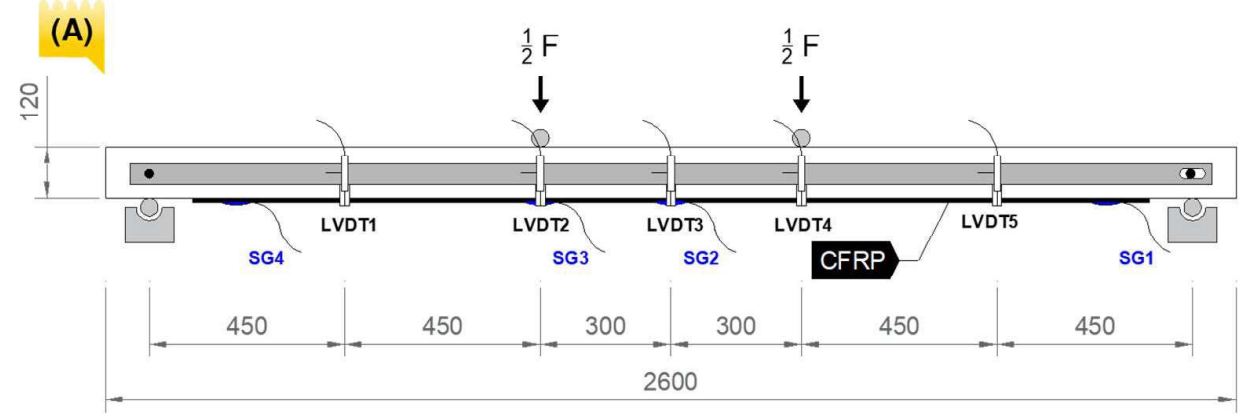

(B)

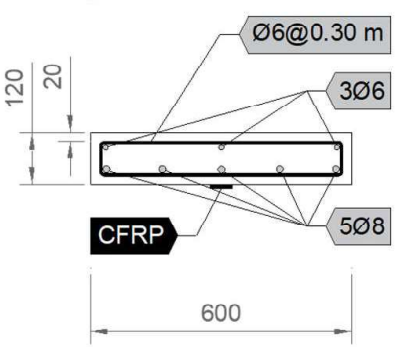

(C)

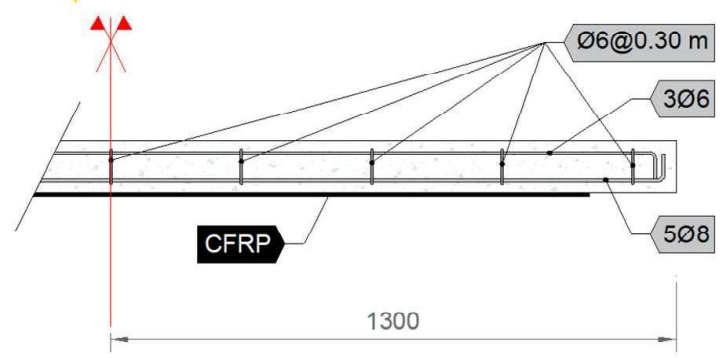

Figure 1. Specimens and test configurations. Note: All units in [mm]

\subsection{Strengthening procedures}

Two anchorage systems were studied in the scope of the present work: (i) the mechanical anchorage system (MA) and (ii) the gradient anchorage (GA). The strengthening procedure of each specimen included several steps. Both systems use common components, e.g. base angles, clamps, aluminium frames, manometer and valves, and hydraulic jacks. The concrete surface was sand blasted in the region where the laminate was applied. Then the typical procedures for the application of the GA and the MA were followed. The main difference between both anchorage systems is the use of heating devices and corresponding procedures for the case of the GA, and the metallic plates in the case of the MA. Additional details can be found in the literature $[2,3]$.

\section{Numerical analysis}

\subsection{General description}

The numerical analysis was carried out using the commercial finite element software DIANA TNO $^{\circledR}$ (version 10.2). All the finite element models (FEM) were two-dimensional assuming plane stress state. Both test configuration and slab's geometry exhibit a symmetry that was considered in the numerical simulations to reduce computational cost. The model geometry, finite element (FE) mesh, loading configuration and boundary conditions used in the analysis of the four experimentally tested specimens are presented in Figure 2.

A regular mesh composed of square finite elements with $10 \mathrm{~mm}$ of edge were used for modelling the 
concrete component of the slabs. Line and interface elements were also used to simulate the reinforcements (steel and CFRP) and interfaces between concrete and CFRP, respectively.

Concrete was discretized using an eight-node quadrilateral isoparametric plane stress elements. A quadratic interpolation and Gauss-Legendre integration scheme was adopted. The longitudinal and transverse steel reinforcement was modelled as embedded reinforcement and the CFRP laminate strip was discretized using a three-node numerically integrated truss elements (CL6TR). The interface between the CFRP and the concrete subtract, was modelled based on the CL12I elements (quadratic interpolation).

A four-point bending test configuration was used on the experimental campaign and the finite element modelling tried to replicate it. Also, three load cases were considered to properly simulate the stress state on each specimen: (i) phase I - self-weight; (ii) phase II - prestress; and, (iii) phase III - monotonic loading of the slab up to the failure.

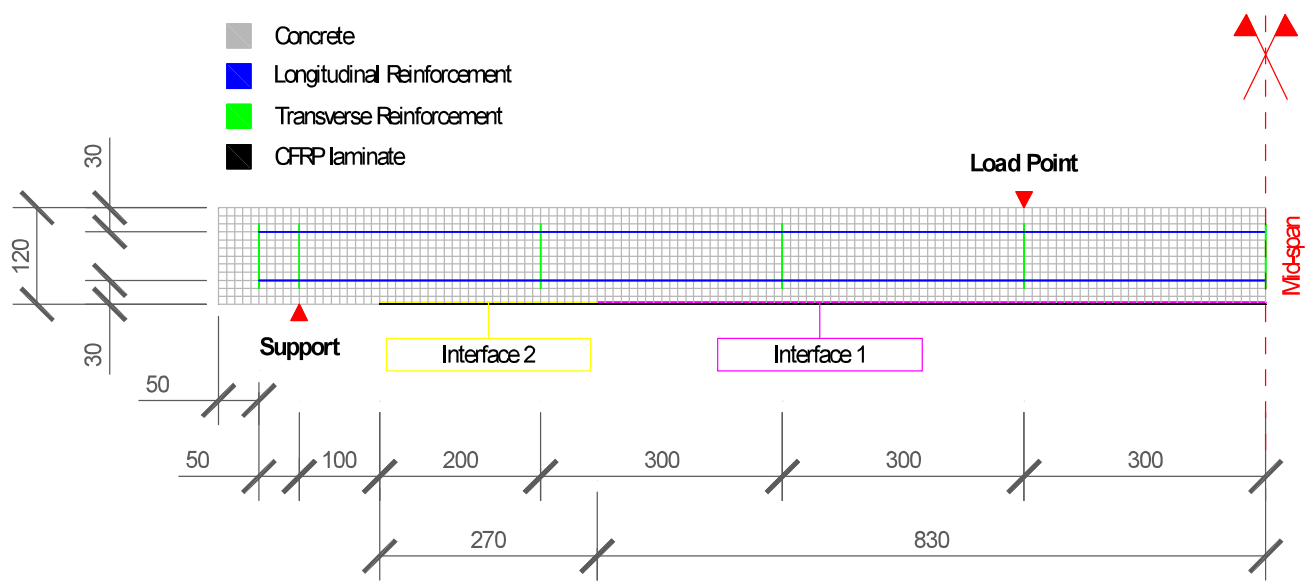

Figure 2. Characteristics of the used models. Note: All units in [mm]

\subsection{Constitutive models}

The different constitutive material models have been used for the simulation of the evolving materials, as shown in Figure 3. Concrete was assumed linear elastic in compression and non-linear in tension (tension softening model according Hordijk etal. [2]). Reinforcing steel was considered elastic-plastic with a simple bi-linear law, and eventually CFRP was modelled linear-elastic up to tensile failure. The interface material model chosen to represent the interface between the concrete and the CFRP laminate is composed by a bilinear bond-slip law proposed by
Lu et al. [5]. This bilinear bond-slip law was used over the full length of the CFRP strip of slabs EBR and GA (Interface 1 and Interface 2, in Figure 2). However, another interface (Interface 2) was considered for the specimen MA (as shown in Figure 2) to simulate the anchorage plates. During the slab's tests the mechanical anchorage exhibit negligible relative displacements between the CFRP laminate and the anchorage plate. In order to properly represent the anchorage plate, Interface 2 was modelled as linear elastic with the normal and shear stiffness modulus equal to $1 \times 10^{6} \mathrm{~N} / \mathrm{mm}^{3}$. 
(A)

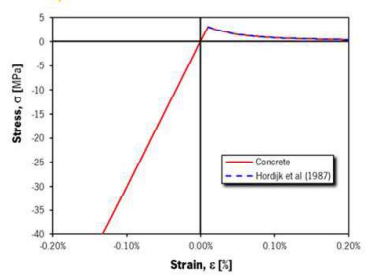

(B)

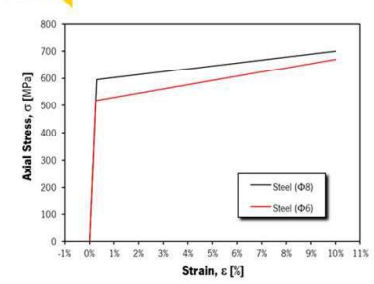

(C)

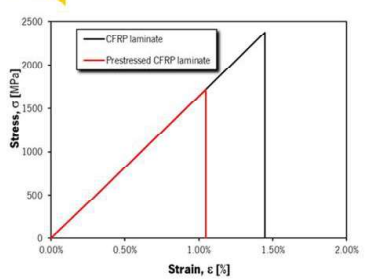

(D)

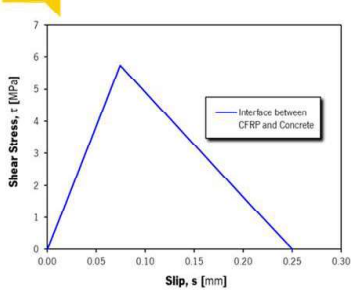

Figure 3. Constitutive material laws for (a) concrete, (b) steel, (c) CFRP and (d) interface between CFRP and concrete.

\section{Results and discussion}

The comparison between the experimental (EXP) and numerical (FEM) results in terms of the applied load and mid-span deflection relationship for all the slabs are shown in Figure 4. In general, these relationships obtained with the numerical simulations presented a very good agreement with the experimental results. These results give an accurate prediction of the deformation response of all slabs during the elastic and cracked stages. In the FE models, the cracking initiation occurred for the same load and mid-span displacement values of the experimental tests. The stiffness of the slabs during the first two stages is identical for the numerical and experimental curves. The steel yielding and ultimate failure are also well captured.

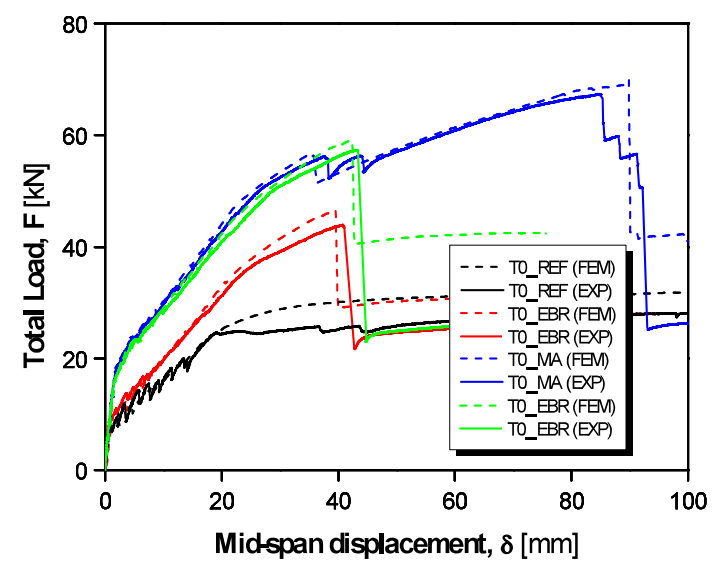

Figure 4. Comparison between the experimental results and numerical predictions in terms of total load versus mid-span displacement.

The ultimate load was well captured in all strengthened slabs. The reference slab tests (TO_REF (EXP)) were stopped at a mid-span deflection of
$100 \mathrm{~mm}$ due to the corresponding LDVT measurement range limitation. Failure mode would in this case most likely be concrete crushing on the top fibre. Failure was also not simulated in the modelled REF slab. However, a similar yielding phase was observed between the experimental and the numerical results, when the total load (F) was close to $30 \mathrm{kN}$ and the mid-span displacement $(\delta)$ was close to $29 \mathrm{~mm}$. It is noteworthy the higher load level on slab TO_REF (FEM) after the steel yielding, when compared with the TO_REF (EXP). This limitation is related to concrete constitutive model selected, more precisely, to the assumption of a linear behaviour in compression.

The ultimate load and mid-span displacement for the numerical productions of slabs TO_EBR, TO_MA and TO_GA were $(\mathrm{F}=39.90 \mathrm{kN} ; \delta=28.97 \mathrm{~mm}),(\mathrm{F}=\overline{70} 0.00 \mathrm{kN}$; $\delta=89.84 \mathrm{~mm})$, and $(\mathrm{F}=57.70 \mathrm{kN} ; \delta=42.45 \mathrm{~mm})$, respectively. During the experimental tests, slabs TO_EBR, TO_MA and TO_GA failed when ( $F=43.98 \mathrm{kN}$; $\delta=30.69 \mathrm{~mm}), \quad(\mathrm{F}=67.46 \mathrm{kN} ; \delta=84.74 \mathrm{~mm})$, and $(F=57.38 \mathrm{kN} ; \delta=43.31 \mathrm{~mm})$, respectively. In essence, the difference between the ultimate load obtained numerically and the ultimate load obtained experimentally varied between $9.3 \%$ and $0.6 \%$.

Like on the experimental results, failure at the interface between the laminate and the concrete was obtained for slabs TO_EBR and TO_GA. Similarly, the numerical simulation predicted the CFRP debonding on the TO_MA slab for the load level of $56 \mathrm{kN}$. This even is represented in the F- $\delta$ curve as one (FEM) or two (EXP) drops. Figure $5 a$ presents the CFRP strain variation in T0_MA. For the same load levels a similar strain values can be observed over the length of the CFRP laminate strip. After the CFRP debonding, the laminate is held by the mechanical anchorages and the numerical simulation considers this phenomenon. 
The variation of the CFRP strain at the mid-span with the total load is presented in Figure $5 b$, for both experimentally tested and numerically predicted. Figure $5 \mathrm{~b}$ clearly shows a good correlation between the experimental and the numerical results. Also, it shows that higher CFRP strains are attained when the slabs are prestressed, thus a more efficient use of the composite material.

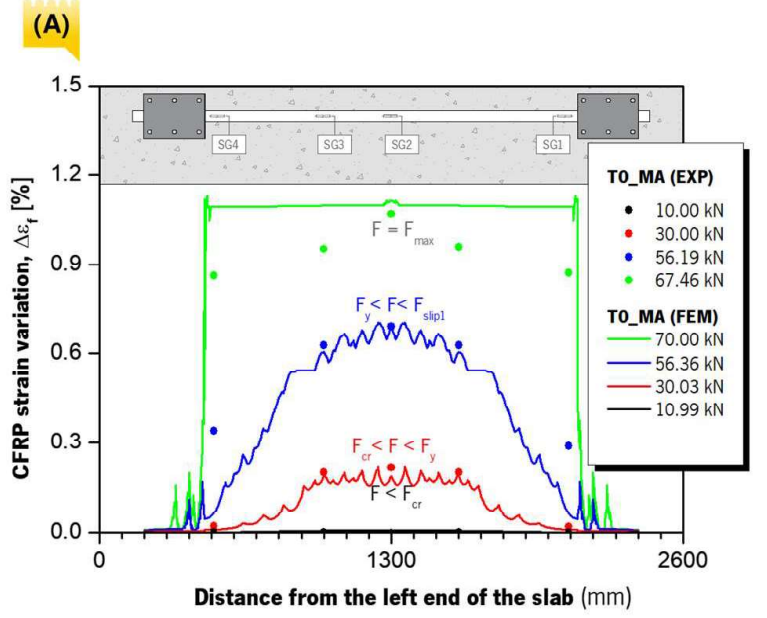

\section{Parametric Studies}

Based on the calibrated numerical models presented in the previous section, two parametric studies were carried out to assess the influence of (i) the prestress level and of (ii) the CFRP laminate geometry on the slabs' structural performance. It should be mentioned that the geometrical properties, loading/boundary conditions and the materials constitutive models described above were kept for both parametric studies.

(B)

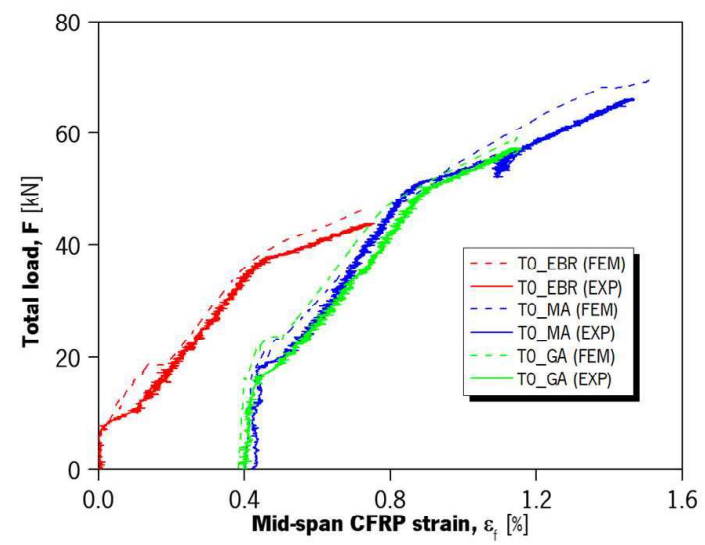

Figure 5. CFRP Strain for slabs experimentally tested (EXP) and numerically predicted (FEM): (a) CFRP strain variation in TO_MA slab; and (b) total load versus CFRP strain.

\subsection{Influence of the level of prestress}

The influence of prestress was one of the main parameters studied in this work. The present parametric study is composed of eight prestressed slabs, four strengthened with the MA anchorage system and the remaining with the GA anchorage system. The levels of prestress ranged between $0.2 \%$ and $0.8 \%$ of CFRP strain. A suffix " $X$ " was added to the label of each slabs, being " $X$ " the equivalent level of CFRP strip prestrain $(0.2 \%, 0.4 \%, 0.6 \%$ and $0.8 \%)$. It should be mentioned that a CFRP strain of $0.6 \%$ has been referred as the upper bound of prestress to be applied. Figure 6 shows the evolution of the mid-span displacement with the total load for the prestressed slabs. As expected, the increase on the prestress level manages to reduce the mid-span displacement and to delay the concrete cracking and steel yielding.
All slabs strengthened with the mechanical anchorage system failed by CFRP rupture, for a load value close to $68.5 \mathrm{kN}$. However, with the increase of the prestress level there is a clear decrease in the structural ductility of the MA slabs (see Figure 6a).

The reduction on the structural ductility can be easily observed through the $\mu_{F}$ and $\mu_{\delta}$ parameters, presented in Table 2. Results show that higher levels of prestress yielded to a decrease on the structural ductility, which is considerable higher on slabs with the MA anchorage system. However, slabs with the MA anchorage system continue to have a better performance in terms of structural ductility and efficiency, mainly because the anchorage plates composing the MA system prevented premature failure. 


\section{(A)}
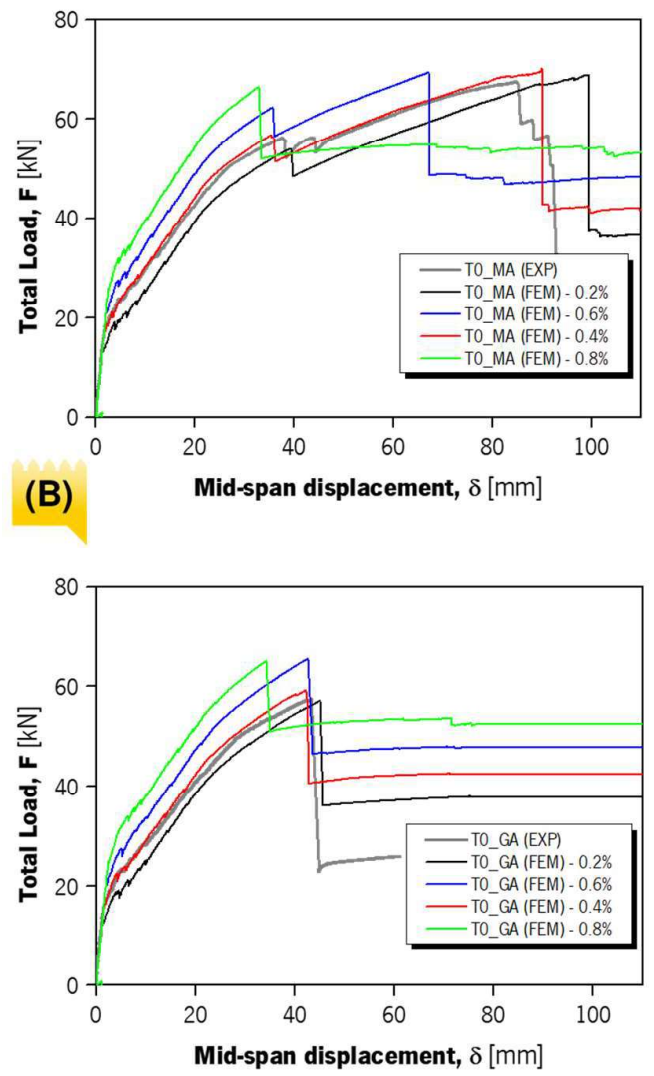

Figure 6. Effect of prestress level on the relationship between the total load and mid-span displacement on slabs (a) MA and (b) GA.

Table 2. Ductility parameters

\begin{tabular}{cccccccccc}
\hline Slab & \multicolumn{3}{c}{$\mu_{\mathrm{r}}=\boldsymbol{F}_{\max } / \boldsymbol{F}_{\boldsymbol{y}}$} & \multicolumn{5}{c}{$\boldsymbol{\mu}_{\delta}=\delta_{\max } / \boldsymbol{\delta}_{\boldsymbol{y}}$} \\
\hline & & & & & & & & \\
\hline CFRP STRAIN: & $\mathbf{0 . 2 \%}$ & $\mathbf{0 . 4 \%}$ & $\mathbf{0 . 6 \%}$ & $\mathbf{0 . 8 \%}$ & $\mathbf{0 . 2 \%}$ & $\mathbf{0 . 4 \%}$ & $\mathbf{0 . 6 \%}$ & $\mathbf{0 . 8 \%}$ \\
\hline TO_MA & 1.52 & 1.46 & 1.30 & 1.13 & 3.93 & 3.94 & 2.85 & 1.40 \\
\hline TO_GA & 1.31 & 1.25 & 1.23 & 1.15 & 1.84 & 1.71 & 1.69 & 1.42 \\
\hline
\end{tabular}

\subsection{Influence of the laminate geometry}

The influence of the CFRP geometry was also assessed in the present study. From the available CFRP laminate geometries, three were selected, with following cross section dimensions: $50 \times 1.2[\mathrm{~mm}], 80 \times 1.2[\mathrm{~mm}]$ and $100 \times 1.2[\mathrm{~mm}]$. Then, nine numerical simulations were carried out to evaluate the influence of the CFRP geometry on the non-prestressed EBR slab, on the prestressed MA slab, and on the prestressed GA slab.
A suffix " $X$ " was added to the label of each slabs, being " $X$ " the laminate width $(50 \mathrm{~mm}, 80 \mathrm{~mm}$ and $100 \mathrm{~mm})$.
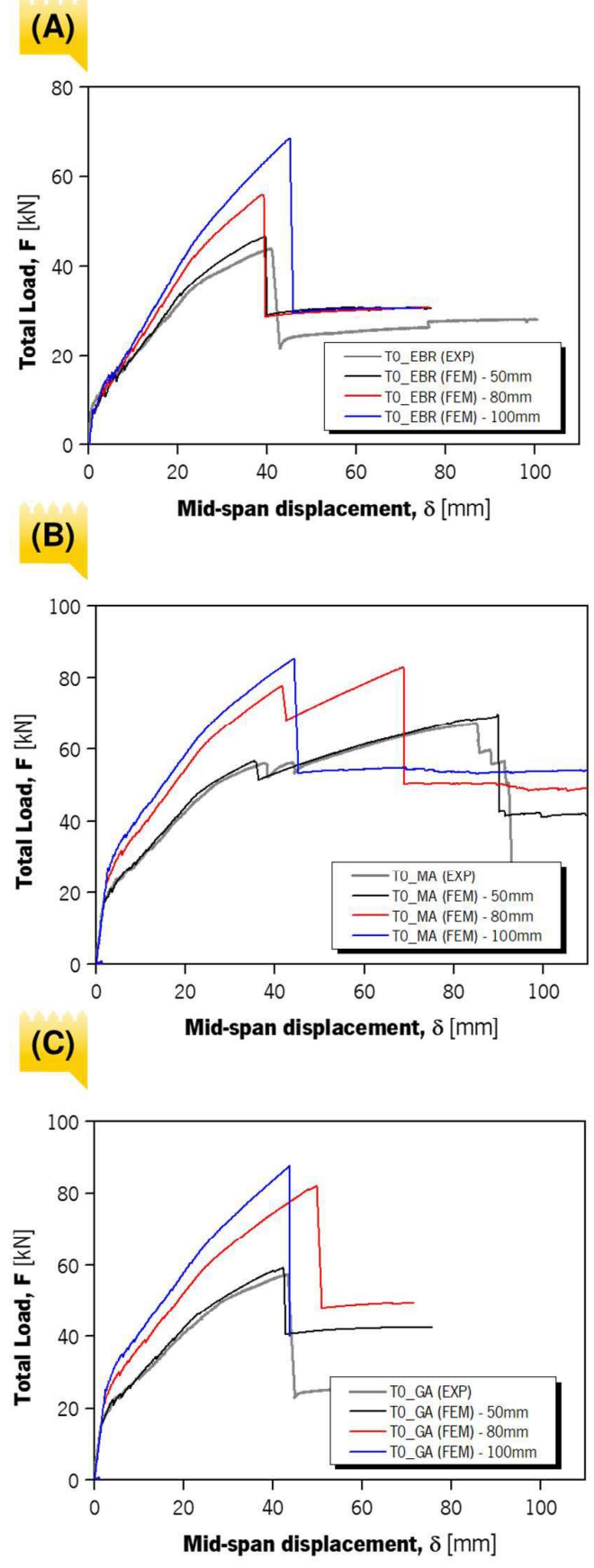

Figure 7. Influence of the laminate geometry on the relationship between the total load and mid-span displacement on slabs (a) EBR, (b) MA and (c) GA.

The evolution of the mid-span displacement with the total load of the simulated slabs is presented in Figure 7. All slabs exhibit the same stiffness during the elastic 
phase and crack initiation, since the amount of reinforcement is not significant compared to the flexural stiffness of the concrete component. After this stage, the concrete contribution on the overall stiffness is significantly reduced and the influence of the CFRP laminate geometry can be noticed in the stiffness of the curves during the cracked phase and yielding phase. The increase on the CFRP cross-section improves the structural performance of all strengthened slabs (TO_EBR, TO_MA and TO_GA), with the delay of the crack initiation and steel yielding and increase on the ultimate load. The increase on the CFRP cross-section and, consequently, prestress load (same level of prestrain - $0.4 \%$ - was used for all specimens), lead to a reduction on the structural ductility, which was higher on slabs with the MA anchorage system. The failure mode observed in slabs with the mechanical anchorage system was CFRP rupture at its maximum tensile capacity. The slabs with the gradient anchorage presented debonding of the laminate as the dominant failure mode.

\section{Conclusions}

This research work presents the numerical simulations of RC slabs strengthened with prestressed CFRP laminates using the mechanical anchorage and the gradient anchorage systems. Two main parts composed this paper: (i) the FE modelling of four slabs, previously tested under four-point bending test configuration; and (ii) a parametric study on the influence of prestress load and CFRP geometry. The obtained results allow to draw the following main conclusions:

1. Good correlations have been found between the experimental results and numerical modelling, for the overall structural behaviour of slabs, including the debonding process and failure modes;

2. The influence of the level of prestress was studied on the parametric study. A significant enhancement of load capacity at crack initiation, steel yielding, and failure was observed, for the slabs with the highest prestress load. However, higher levels of prestress yielded a decrease on the structural ductility, which is considerably higher on slabs with the MA anchorage system;

3. The increase on the CFRP cross-section improved the structural performance of all strengthened slabs (TO_EBR, TO_MA and TO_GA), with the delay of the crack initiation and steel yielding and increase on the ultimate load. However, the increase on the CFRP cross-section lead to the increase of the prestress load and, consequently reduced the structural ductility.

\section{Acknowledgements}

This work is supported by FEDER funds through the Operational Program for Competitiveness Factors COMPETE and National Funds through FCT Portuguese Foundation for Science and Technology under the project FRPLongDur - POCI-01-0145-FEDER016900 (FCT PTDC/ECM-EST/1282/2014) and partly financed by the project POCI-01-0145-FEDER-007633.

The authors thank all the companies that supported and contributed for the development of this study, mainly: S\&P Clever Reinforcement Ibérica, Tecnipor, Vialam, Hilti, Artecanter and Nova Europa. The second author also wishes to acknowledge the grant SFRH/BD/99309/2013 provided by FCT.

\section{References}

[1] Michels J, Sena-Cruz JJ, Czaderski C, Motavalli M. Structural Strengthening with Prestressed CFRP Strips with Gradient Anchorage. J Compos Constr 2013;17:651-61. doi:10.1061/(ASCE)CC.19435614.0000372.

[2] Correia L, Teixeira T, Michels J, Almeida JAPP, Sena-Cruz J. Flexural behaviour of RC slabs strengthened with prestressed CFRP strips using different anchorage systems. Compos Part B Eng 2015;81:158-70. doi:10.1016/j.compositesb.2015.07.011.

[3] Correia L, Sena-Cruz J, Michels J, França PM, Pereira E, Escusa G. Durability of RC slabs strengthened with prestressed CFRP laminate strips under different environmental and loading conditions. Compos Part B Eng 2017;125:71-88. doi:https://doi.org/10.1016/j.compositesb.2017.05.04 7.

[4] Silva P, Fernandes P, Sena-Cruz J, Xavier J, Castro F, Soares $D$, et al. Effects of different environmental conditions on the mechanical characteristics of a structural epoxy. Compos Part B Eng 2016;88:55-63. doi:10.1016/j.compositesb.2015.10.036.

[5] Lu XZ, Teng JG, Ye LP, Jiang JJ. Bond-slip models for FRP sheets/plates bonded to concrete. Eng Struct 2005;27:920-37. 